\title{
Aspectos financieros y legales diferenciales de los microcréditos
}

\section{Ma del Carmen López Martín* I Adolfo Rodero Franganillo*}

Palabras clave: microcréditos, exclusión financiera, entidades financieras tradicionales, pobreza, microcréditos en España.

Key words: microcredits, financial exclusion, traditional financial institutions, poverty, microcredits in Spain.

\section{Introducción}

En el año 2006 se ha concedido el premio Nobel de la Paz a Muhammad Yunus, figura clave de los microcréditos y fundador del Grameen Bank (el también denominado banco de los pobres). Así, se ha mantenido de actualidad este instrumento financiero después de que el año 2005 fuera declarado el "Año Internacional del Microcrédito" por parte de Naciones Unidas con los propósitos, entre otros, de: generar conciencia del público, sensibilizar a los gobiernos acerca de las necesidades financieras de los más necesitados y contribuir a la consecución de los Objetivos de Desarrollo del Milenio.

Desde un punto de vista más académico, los microcréditos suelen incluirse dentro de los llamados "instrumentos financieros alternativos", que son aquéllos que persiguen el desarrollo de actividades económicas o no lucrativas de difícil financiación en los circuitos financieros tradicionales, debido al carácter de las actividades o la situación económica del emprendedor. Tras ellos subyace una concepción del ahorro y la inversión que, yendo más allá de lo meramente lucrativo, se fija más en la rentabilidad social de las inversiones y en la responsabilidad social del ahorrador ${ }^{1}$, ocupando un lugar primordial entre sus objetivos garantizar la inserción de hombres y mujeres, a través de aspectos como el uso de las actividades económicas para insertar a los excluidos del sistema y la colocación de dichas actividades

* Profesores de la Facultad de Ciencias Económicas y Empresariales - ETEA.

' B. GUTIÉRREZ (2001), p. 1. 
dentro de estructuras institucionales (cooperativas, grupos de ayuda mutua...) que faciliten las relaciones humanas.

Si nos fijamos en las instituciones que participan en los que podríamos llamar mercados financieros tradicionales (fundamentalmente, bancos, cajas de ahorros y cooperativas de crédito), encontramos que hay determinadas personas que no tienen acceso a la financiación $\mathrm{o}$, de forma más general, a los servicios de estas entidades; ello se debe a distintos motivos, como el hecho de que quienes solicitan financiación no encajan dentro del perfil establecido de "empresario", el desconocimiento de la lógica de la economía social (lo que aumenta las dudas sobre la viabilidad de los proyectos que emergen de ésta), la ausencia de garantías que respalden los proyectos (o si las tienen, se trata de estructuras económicas no tradicionales y/o se colocan en mercados de "alto riesgo"), la falta de experiencia en el ámbito empresarial por parte del que solicita la financiación (un individuo o una organización) lo que hace necesario facilitar asistencia o formación en dicha área, etc.

Teniendo en cuenta lo anterior, en este artículo se intenta realizar una valoración de los microcréditos desde el punto de vista financiero y legal. Para ello, se comienza presentando cómo es el circuito bancario y crediticio tradicional, frente al que surgen los microcréditos, cuyas principales características son explicadas a continuación; igualmente, se comparan con las operaciones tradicionales para analizar las principales diferencias entre ambas. El punto 3 aborda la práctica de estas operaciones en España y las entidades que suelen llevarla a cabo. Finalmente, en las conclusiones, se indican las posibilidades que este instrumento presenta y se valora su posible utilidad.

\section{El esquema bancario tradicional. El caso español}

El funcionamiento de los microcréditos difiere del de las operaciones de las entidades tradicionales de crédito (en España son los bancos, las cajas de ahorro y las cajas rurales, principalmente). Por ello nos parece importante recordar cómo son las operaciones de estas entidades para compararlas con los microcréditos y analizar, en su caso, las limitaciones de estos últimos.

\section{I.I.Algunas cuestiones generales}

Las instituciones que realizan estas operaciones "tradicionales" son, como ya se ha indicado, las "entidades de crédito", grupo que comprende los bancos, las cajas de ahorro, las cooperativas de crédito, el Instituto de Crédito Oficial (ICO) y los denominados "establecimientos financieros de crédito".

Nos interesan especialmente los dos primeros: los bancos son sociedades anónimas y las cajas de ahorro tienen un origen fundacional; ambos grupos de entidades realizan operaciones de intermediación financiera. El número de oficinas de bancos y cajas es muy elevado, existiendo una o varias oficinas en todas las ciudades y pueblos españoles, incluso en los más pequeños. 
Estas entidades tienen que cumplir dos coeficientes: a) coeficiente de caja, que les obliga a mantener al menos un $2 \%$ de los depósitos y otros pasivos en forma de medios líquidos (tesorería); y b) coeficiente de solvencia, que comentamos más adelante.

La cuenta de resultados de bancos y cajas presenta normalmente beneficios que pueden ser bastante elevados. Por ejemplo, en 2005, el conjunto de la banca consiguió unos beneficios de 9.518 millones de euros (un 0,9\% del balance total medio, o 10,6\% de los recursos propios); las cajas de ahorro durante el mismo periodo alcanzaron unos beneficios de 5.877 millones de euros (0,8\% del balance total medio, o 10,7\% de los recursos propios). Estos beneficios proceden principalmente del margen de intermediación (diferencia entre los intereses de las operaciones activas y los intereses de las pasivas), de las comisiones (que cada vez tienen mayor importancia) y de las plusvalías. Se puede afirmar, por consiguiente, que estas entidades tienen una alta rentabilidad.

Por último es importante señalar que los bancos, cajas de ahorro y cooperativas tienen unos Fondos de Garantía de Depósitos, formados por aportaciones de las propias entidades y, en el pasado, del Banco de España, que permitirían la devolución de los depósitos a los clientes en caso de insolvencia de alguna entidad.

\section{I.2. Los recursos propios}

Las entidades de depósito (los ya citados: bancos, cajas de ahorro y cooperativas de crédito) muestran en el pasivo de su balance los "recursos propios" que en el documento publicado por el Banco de España figuran bajo la denominación de "capital y reservas". Su contenido está constituido por las aportaciones de los socios (en los bancos y cooperativas) para nutrir el capital, o por las aportaciones de los fundadores (en las cajas de ahorros) al fondo fundacional o patrimonial; además se incluyen la formación de reservas procedentes de los beneficios obtenidos, en su caso, a lo largo del tiempo.

A 31-8-2006, la banca tenía unos recursos propios de 86.486 millones de euros, mientras que el capital y reservas de las cajas de ahorro ascendía a 70.028 millones de euros a 30-9-2006. Estas cifras se compensan, aproximadamente, con las siguientes partidas del activo: "Activo fiio", cartera de "acciones y participaciones" y "Efectivo en caja". Aunque no existe ninguna regla que determine esta distribución, lo habitual es que, efectivamente, las entidades destinan los recursos propios a inversiones que, en cierto modo, podemos considerar que no son las típicas de la banca. Los préstamos y los valores de renta fija no se financian con recursos propios. No olvidemos que estamos hablando de intermediarios financieros, que sirven de puente entre los ahorradores y los inversores o consumidores.

¿Qué papel juegan entonces estos recursos propios? Sirven de garantía de la actuación financiera de estos entes: en caso de que una entidad bancaria sufra algún percance (dificultades de pagos, quiebra, etc.) habría que acudir a estos fondos para atender a sus obligaciones. Es evidente que su volumen no llega nunca a cubrir el 100\% de dichas obligaciones. Sobre esto volveremos más adelante. 


\section{I.3. Los recursos ajenos}

También en el pasivo de las entidades de crédito aparecen los recursos ajenos con las denominaciones de "depósitos" y "valores distintos de acciones y participaciones" (vulgarmente conocidos como "valores de renta fija"). Corresponden a las cantidades que su clientela les confía, a cambio de unos intereses, no siempre, y una mayor seguridad de los recursos ahorrados o de la tesorería y de una mayor facilidad de manejo de dicha tesorería. En la banca, los recursos ajenos tenían un volumen, a 31-8-2006, de 1.045 .553 millones de euros; en las cajas, el 30-9-2006, estos recursos se elevaban a 808.796 millones de euros.

¿A qué se destinan los recursos ajenos? Financian los "préstamos y créditos" y la cartera de "valores distintos de acciones". Es decir, los recursos captados en el mercado se destinan a financiar las inversiones o parte del consumo de sus clientes. Aquí aparece claramente el carácter intermediador de las entidades que captan recursos en los mercados y los prestan en estos mismos mercados. En resumen, normalmente, las entidades de depósito no prestan su capital o reservas, sino los fondos de sus clientes.

\subsection{Las garantías}

En la mayor parte de los países existe una gran preocupación de que las operaciones bancarias estén debidamente garantizadas para salvaguardar la seguridad y estabilidad de las propias entidades, para evitar situaciones de crisis generalizadas $y$, en último término, en beneficio de los intereses de su clientela. Estas garantías pueden ser de dos tipos: a) garantías proporcionadas por el deudor en las operaciones de préstamos o en los empréstitos en forma de valores; b) la garantía de las propias entidades, bien a través del coeficiente de solvencia o de recursos propios, bien como resultado de la supervisión bancaria.

\section{I.4. I. Garantía de las operaciones}

Hasta ahora, los deudores de las entidades aportan una garantía para asegurar el cumplimiento de sus compromisos de pagar los intereses y devolver el principal de la operación. Una de las fórmulas es la garantía hipotecaria ligada a inversiones inmobiliarias. La finca rústica o urbana queda vinculada al crédito de forma que la entidad tendría preferencia en el cobro, en caso de venta, o en la propiedad, en caso de incumplimiento. Otra operación son los créditos empresariales o personales, sin carácter hipotecario, cuya garantía consiste en la presencia de avalistas, personas que se comprometen a pagar las cantidades correspondientes en caso de incumplimiento; en cuanto a las empresas, la garantía viene dada, en general, por el balance de la sociedad. Todo esto va dirigido a asegurar el cumplimiento de las obligaciones, en el peor de los casos, la recuperación de todos o parte de los recursos, en beneficio, no sólo de la entidad de crédito, sino también de sus clientes de pasivo que se sentirán seguros acerca de la posible disponibilidad de sus depósitos. Todo lo anterior es aplicable, asimismo, para las emisiones de valores de renta fija.

Muy recientemente, se han extendido también los créditos al consumo, de concesión casi automática; éstos tienen a veces algún tipo de garantía y en otros casos la ausencia de ésta queda compensada por unos intereses más elevados que los de los préstamos tradicionales. 


\section{I.4.2. Solvencia de las entidades}

Existen dos mecanismos que pueden contribuir a mantener la solvencia de las entidades: a) el coeficiente de solvencia o de recursos propios; y b) la supervisión de las entidades de depósito.

En el coeficiente de solvencia se tiene en cuenta la relación de las inversiones realizadas con los recursos propios. A cada uno de los distintos tipos de inversiones (riesgos frente a las administraciones públicas, riesgos frente a entidades financieras, préstamos hipotecarios, activos reales, otros tipos de créditos o préstamos) se le aplican diferentes porcentajes que son más elevados en las operaciones con mayor riesgo y más reducidos en las de mayor seguridad. Las inversiones ponderadas se relacionan con los recursos propios obteniendo un tanto por ciento que no puede ser inferior a 8 .

El Banco Internacional de Pagos de Basilea ha elaborado conjuntamente con los bancos centrales y las entidades de crédito europeas una nueva estructura del coeficiente de solvencia conocida vulgarmente como "Basilea II"; sus principios tienen el mismo fundamento: asegurar la solvencia en función del riesgo soportado por las entidades, pero establece un sistema menos mecánico, adaptándolo a cada institución concreta. Parece que, en general, la aplicación de este nuevo sistema de Basilea Il podrá elevar la necesidad de recursos propios, al menos en algunos casos.

Existen además unos límites a los grandes riesgos soportados por las entidades del sistema y a la concentración de riesgos en cada una de ellas.

Todos estos mecanismos tratan de asegurar la solvencia de las entidades incluso en casos de retirada de recursos o de que se produzcan fallidos de moderada importancia.

La supervisión de las entidades es realizada por los bancos centrales o emisores de cada país, que a través de visitas de inspección, envíos obligatorios de documentos contables a dichos bancos, análisis de los balances y cuentas de resultados, servicios de reclamaciones, registros de impagados, etc. tratan también de asegurar la solvencia y estabilidad de las distintas instituciones y del sistema en su conjunto. En el caso de la Unión Europea se han dado pasos importantes para lograr que la supervisión tenga un alcance europeo; esta ampliación del ámbito de validez de la supervisión no se ha alcanzado todavía al cien por cien.

Todas las normas en relación con la solvencia están diseñadas en beneficio de las propias entidades y de sus clientes, sobre todo de pasivo, pero también buscan la estabilidad del sistema para evitar las crisis sistémicas de carácter internacional que se han producido en el pasado (México, Brasil, países asiáticos, etc.)

\section{I.5. El trámite de los préstamos y de las emisiones}

La tramitación de los préstamos o créditos ha sido, tradicionalmente, muy compleja. De forma simplificada, podemos señalar las siguientes partes de los trámites de los créditos:

- Solicitud del crédito en los modelos proporcionados por la entidad. Estas solicitudes van acompañadas de una documentación: en el caso de las personas físicas, declaración de 
bienes, del IRPF, de la propiedad de los inmuebles y fincas, en su caso; en el caso de empresarios, balance y cuenta de resultados de los últimos años, memorias de la sociedad, y otros documentos legales.

- La entidad somete a estudio la solicitud, aprobándola en su caso; la aprobación será realizada por un órgano, que será al que compete la decisión en función del importe solicitado.

- Una vez aprobado, se procede a la instrumentación legal, normalmente con intervención de un fedatario público (notario). El documento de aprobación será una póliza de crédito, aunque también existe la instrumentación en efectos financieros, aunque ésta última es ya menos frecuente.

- En los créditos hipotecarios, hay que establecer una hipoteca sobre los bienes inmuebles, con la intervención del notario y con anotación en el registro de la propiedad.

- En cuanto a los créditos personales, hay que instrumentar la participación de los avalistas mediante un documento que recoja su compromiso y en el que se incluye una declaración de bienes y, en su caso, la del IRPF. La firma de los avalistas también se hace, normalmente, ante notario.

- Completada la aprobación, se realiza un cuadro de amortización que recogerá los pagos periódicos que deberá efectuar el prestatario (incluyendo intereses, comisiones y devolución del principal).

- La entrega de los fondos se lleva a cabo mediante abono en una cuenta del total del préstamo, o mediante apertura de una cuenta de crédito cuyo límite coincide con el crédito concedido (aunque se utilizan indistintamente, el término "préstamo" corresponde al primer caso y el de "crédito" al segundo).

- Los gastos de un crédito están constituidos por los intereses (mensuales, trimestrales, etc.), es decir, el coste de la utilización de los recursos; las comisiones de diversos tipos (de estudio, de apertura, de disponibilidad, etc.); y los derechos de la notaría, del registro, etc., en su caso.

La duración de todo el proceso varía según el tipo de crédito, su volumen, etc. Fácilmente, requiere varios meses y en los casos más sencillos llegará algunas semanas o un mes. Recientemente, se han extendido los créditos al consumo cuya tramitación es mucho más simple y más rápida; a veces basta con una petición que se resuelve de forma casi automática.

La emisión de valores distintos de acciones (de renta fija) requiere un proceso largo y complejo que será realizado por el emisor. La tramitación de estas operaciones comprende algunos de los pasos indicados anteriormente, además de la comunicación al organismo supervisor correspondiente (en España, la Comisión Nacional del Mercado de Valores) el anuncio de la emisión y la intervención de distintas entidades (aseguradoras, comercializadoras, etc.) la inversión en estos valores por las entidades de crédito se hará mediante la suscripción o compra en el mercado, con intervención de una sociedad o agencia de valores, en ciertos casos. 


\section{Los microcréditos: concepto y características generales}

En la Cumbre sobre microfinanzas de 1997 se acordó la siguiente definición de los microcréditos: "Programas de concesión de pequeños créditos a los más necesitados entre los pobres para que puedan poner en marcha pequeños negocios que generen ingresos para mejorar su nivel de vida y el de sus familias" 2 . También, destacando algunas de sus características, podría decirse que son "préstamos sin aval concedidos por entidades benéfico-sociales, por algunas entidades de crédito de carácter social (como las cajas de ahorros en España), por ONG, y en algún caso, por otras entidades de crédito, a favor de personas pobres pero que tienen un proyecto empresarial" ${ }^{\prime \prime}$.

De ambas definiciones se deducen sus características más importantes:

- Es un instrumento financiero que implica un trasvase de recursos entre un prestamista y un prestatario, el cual se compromete a devolverlos en los plazos y condiciones establecidos, no se trata, por tanto, de donaciones o subsidios.

- Son préstamos de pequeña cuantía para individuos o empresarios, que no son concedidos por la banca convencional debido a la pequeña cuantía solicitada, la naturaleza de la actividad para la que se solicita o la falta de garantías del solicitante.

- En general, puede afirmarse que las personas que solicitan los microcréditos están en situación de "exclusión" social y financiera, y que normalmente pertenecen al ámbito de la denominada "economía informal". De esta forma, concediendo microcréditos se busca reducir las diferencias de acceso a los instrumentos y servicios financieros.

- Puesto que los receptores de los microcréditos son personas que no tienen acceso al sistema bancario tradicional, la financiación que reciben no puede seguir los esquemas clásicos, en particular, en lo relativo a la existencia de garantías para responder de la devolución del crédito, aspecto que se suple en parte con otros mecanismos ${ }^{4}$.

- El importe recibido en los microcréditos es, como su propio nombre indica, generalmente muy reducido. De esta forma, en los países menos desarrollados, apenas se llega a unos cuantos dólares, mientras que en otros ámbitos se llega a cantidades algo más elevadas. Así, según algunas fuentes, los importes pueden oscilar entre los 100 ○ 200 \$ en países de Asia o África, llegando a los 1.000\$ de media en América, o incluso $10.000 €$ en Europa occidental.

- Otra cuestión importante son los intereses que deben abonar las personas que se benefician de estas operaciones. Hay ocasiones en que se sitúan alrededor del 5,5\%, aunque en los

${ }^{2}$ Cumbre sobre microfinanzas, ver sitio web http://www.microcreditsummit.org

${ }^{3}$ A. RODERO (2006), "Los microcréditos y los créditos tradicionales", I Seminario sobre Microcréditos organizado por ASOLCOR, Córdoba, mimeo.

${ }^{4}$ Más adelante se realizan algunos comentarios adicionales sobre esta cuestión. 
estados más pobres se elevan hasta el 10\%, o incluso valores superiores (desde el 12\% a incluso tasas cercanas al $25 \%$ ). Aunque es posible que en ciertos ámbitos los tipos de interés aplicados puedan parecer excesivos, hay que tener presente que los que acceden al microcrédito, al quedar fuera del circuito bancario tradicional, no tendrían acceso a la financiación que necesitan o sólo a los fondos proporcionados por los que podrían denominarse intermediarios financieros informales (dentro de éstos se encuentran los prestamistas individuales, comúnmente conocidos como usureros, cuyos tipos de interés son claramente superiores a los existentes en el mercado, al quedar fuera de toda regulación). En cualquier caso, antes de calificar un tipo de interés concreto como muy elevado, habría que compararlo con los existentes en el país para las operaciones incluidas en lo que sería el esquema bancario tradicional ${ }^{5}$. Por otro lado, parece comprobado que los destinatarios de los recursos deben pagar intereses por los mismos para valorarlos adecuadamente y no considerarlos como un regalo sin aprovecharlos convenientemente.

- Los plazos de las operaciones son generalmente cortos, lo que, en parte, se justifica por los reducidos importes, pero también por la solvencia de las entidades y por el destino de los recursos.

- Dado el importe reducido de los préstamos y el corto plazo de amortización, la devolución de los recursos también se realiza con una periodicidad elevada (es decir, cada poco tiempo) y por importes también pequeños. Esto en parte facilita los reembolsos, pero por otro lado lleva a que incluso se lleven a cabo devoluciones con periodicidad quincenal o semanal.

- El destino de los recursos, en principio, no es financiar los gastos de consumo, sino la realización de una actividad que permita al beneficiario obtener unos ingresos que hagan posible la devolución de los recursos recibidos, junto con los intereses. Esta actividad, no obstante, no le viene impuesta al prestatario, sino que es él mismo el que se decide por ella.

- Con este instrumento, en definitiva, se pretende influir sobre la situación de pobreza de los prestatarios, de forma que se consiga que los pobres salgan de su situación y mejoren sus niveles de vida.

- Muchos servicios de microfinanzas están destinados a las mujeres. El ejemplo de Grameen Bank demostró que las mujeres son más cumplidoras al devolver los préstamos otorgados (casi el 98\% de los casos), y que el impacto de este aumento de recursos es mayor si el jefe de familia es una mujer. Es pues la familia entera la que se beneficia, en materia de salud y educación, por ejemplo.

El origen de las operaciones de microcréditos, como es conocido, es Bangladesh, el denominado Grameen Bank. Desde ahí se ha extendido a otros ámbitos geográficos. El número de países en los que se conceden microcréditos es muy elevado, además de Bangladesh: India, Bolivia, Rusia, Zambia, Angola, Mozambique, países del África Occidental, El Salvador, Perú, Polonia, España, etc.; pero es especialmente importante en los países menos desarrollados debido a que es ${ }^{5}$ En algunas fuentes (véase H. I. LATIFEE, p. 28) se indica que los microcréditos tienen unas tasas de interés que no superan
en más de 10 puntos porcentuales las aplicadas por los bancos comerciales. 
utilizado por entidades que se especializan en cierta medida en emplear este instrumento ya que lo consideran adecuado para fomentar el desarrollo de las poblaciones más desfavorecidas.

Un concepto relacionado con los microcréditos es el de microfinanzas, que, en principio no es sinónimo del primero, sino que corresponde a unas actividades más amplias y variadas, ya que no sólo facilitan recursos a las microempresas para financiar sus inversiones o sus necesidades de tesorería, sino que realizan algunas operaciones que se incluyen dentro del circuito bancario tradicional, pues captan depósitos de su clientela, emiten valores suscritos por ésta, etc.

Como puede observarse, algunos de los aspectos que caracterizan los microcréditos difieren sustancialmente de las comentadas anteriormente y que podrían encuadrarse en lo que se ha denominado el "esquema bancario tradicional". Los más significativos se comentan a continuación, diferenciándolos de los anteriores.

\section{I. La demanda de microcréditos}

Como ya se ha comentado, los destinatarios de los recursos en las operaciones de microcréditos son, generalmente, personas que se encuentran en situación de "exclusión financiera" o "exclusión social". Estos dos términos, que en principio pueden parecer similares, tienen detrás situaciones diferentes. Así, el término "exclusión social" hace referencia al acceso restringido, con cierto grado de permanencia en el tiempo, a los derechos sociales, como el derecho al trabajo, a la vivienda, a un sistema sanitario, a la educación o a la vida social debido a la manera en que los servicios sociales están organizados o por la vulnerabilidad de la situación económica, social y política. Por lo tanto, estaríamos ante, por ejemplo, las condiciones en las que se encuentra gran parte de la población en los países menos desarrollados.

Por su parte, la "exclusión financiera" hace referencia a la falta de acceso a los productos y servicios que ofrece el sistema financiero formal, es decir, cuando no se pueden tener instrumentos financieros -medios de pago o de ahorro- distintos al dinero en efectivo. Esta falta de acceso puede deberse a la imposibilidad física de acceder a una entidad financiera o a la incapacidad personal para acceder a una de estas entidades (la persona no posee los requisitos que el sistema financiero formal solicita). En general, se distingue entre la exclusión financiera parcial (posibilidad de acceder a ciertos productos financieros pero no a un préstamo) y la exclusión financiera total (imposibilidad de acceder a cualquier producto o servicio financiero, teniendo como única salida los servicios financieros informales -los usureros-).

La exclusión financiera se presenta, por ejemplo, en los países desarrollados y afecta a determinados colectivos que no tienen acceso a las operaciones que hemos encuadrado dentro de lo que sería el esquema bancario tradicional, tanto desde el punto de vista de los recursos, como desde el punto de vista de las inversiones (créditos). Así, si nos fijamos en el caso de España, los microcréditos se han dirigido generalmente a personas que, como se acaba de indicar, pertenecen a ciertos grupos que se pueden considerar desfavorecidos dentro de nuestro contexto socioeconómico. Tomando como referencia la línea de microcréditos del ICO, los posibles beneficiarios debían pertenecer a uno de los siguientes grupos: mayores de 45 años, hogares monoparentales, inmigrantes, mujeres, discapacitados y parados de larga duración fundamentalmente. 
Por otra parte, también los microcréditos tienen como finalidad la lucha contra las situaciones de pobreza y, para ello, la concesión de los recursos se vincula a la existencia de un proyecto empresarial viable y, en los países desarrollados, el grado de exclusión en el que se encuentran los destinatarios de los fondos se puede valorar, en cierto modo, al tenerse en cuenta el hecho de no tener ningún tipo de garantías para poder acceder a este tipo de operaciones.

Comparando todo esto con las características habituales en los clientes que reciben los créditos de las entidades de crédito (centrándonos en España) encontramos rasgos claramente diferentes: generalmente, éstas son personas que realizan habitualmente operaciones con el sistema financiero que tienen distinto grado de complejidad (cuentas, tarjetas de débito y crédito, fondos de inversión, planes de pensiones, etc.). La financiación recibida no tiene como objetivo la mejora de los niveles de vida, sino, en primer lugar, la financiación de la adquisición de vivienda y, secundariamente, de bienes de consumo; no hay por tanto vinculación a un proyecto empresarial. Finalmente, para la obtención del crédito se deben aportar una serie de garantías que minimicen el riesgo que corre la entidad de crédito en la concesión del préstamo.

\subsection{Los trámites en los microcréditos}

Como ya se ha comentado anteriormente, el proceso de concesión de un crédito en el esquema bancario habitual puede llegar a dilatarse en el tiempo hasta alcanzar varios semanas e incluso meses, además de presentar, en ocasiones, un cierto grado de complejidad, que implica incluso la necesidad de llegar a contar con asesoramiento para poder realizarlo. Desde este punto de vista, los microcréditos suponen una forma de superar estos obstáculos, sobre todo si se tiene en cuenta que los agentes que realizan las operaciones en una gran mayoría, carecen de formación y experiencia financiera. Algunas manifestaciones de esto son:

- Las solicitudes son simples, de forma que el posible prestatario tiene que aportar tan sólo una información básica acerca de sí mismo y del negocio que quiere acometer, acompañado de una documentación que, en caso de existir, es mínima.

- Dadas las condiciones en las que se encuentran los posibles beneficiarios, el periodo de duración del proceso es reducido. Para ello, el tiempo de tramitación de las operaciones disminuye en comparación con el de las operaciones habituales y la respuesta se ofrece rápidamente: a los pocos días o semanas de la solicitud.

- La instrumentación de la operación es sencilla. En bastantes casos se produce la firma de un contrato redactado en términos muy simples y de longitud reducida (muchas veces es una carilla de la hoja con los aspectos básicos de la operación y la firma de ambas partes), lo cual es lógico tanto para garantía de la entidad como por el hecho de suponer un grado de compromiso "público" del prestatario en la devolución de los fondos; no obstante, en muchas ocasiones (sobre todo en las operaciones realizadas en los países en desarrollo) es más habitual que ni siquiera exista este contrato simplificado, pues el beneficiario de los fondos puede que no sepa ni leer ni escribir.

- Lógicamente, todo lo anterior exige por parte de la entidad prestamista un mayor esfuerzo en el conocimiento de la realidad del peticionario, para lo cual debe situarse muy cercana a él. 
En este sentido, la cercanía física de las entidades a los clientes es muy importante. Aunque en España esto no nos llama la atención, en otros sistemas financieros esta abundancia de oficinas no es habitual. Por otra parte, los procedimientos de estudio y tramitación de las operaciones deben ser ágiles, lo que exige no sólo un grado de preparación por parte del personal encargado sino también la descentralización de la toma de decisiones. Esto tiene importancia por su repercusión en los costes operativos, como se comenta más adelante.

\subsection{Las garantías en los microcréditos}

Ya se ha indicado que en la mayor parte de los países existe una gran preocupación porque las operaciones cuenten con una garantía adecuada para conseguir así la seguridad de las entidades y evitar crisis generalizadas, lo que en última instancia constituye una protección para la clientela. Estas garantías proceden de las mismas operaciones (garantías reales o personales, así como la presencia de avalistas); por otra parte existe un coeficiente obligatorio, el de solvencia, que las refuerza a través de los recursos propios. En el ámbito de los microcréditos, sin embargo, esto no es así, ya que los destinatarios de los recursos no aportan ningún tipo de garantía "formal". Sin embargo, esta circunstancia no implica una falta de seguridad de las operaciones ya que, si sucediera así, no se garantizaría la supervivencia de la entidad financiera y el sistema terminaría por quebrar; por lo tanto, cabría hablar más bien de garantías "implícitas".

- La primera fuente de garantías procede del propio proyecto a acometer por el prestatario: los ingresos derivados del mismo deben ser los que garanticen, en última instancia, la devolución, de ahí que cobre gran importancia que este proyecto no venga impuesto, así como la existencia de cursos de capacitación y asistencia técnica, que van a venir a colaborar para lograr su viabilidad (como veremos después, en esto pueden ayudar ciertas entidades a las instituciones financieras).

- Pero el proyecto no lo es todo; en los microcréditos, aunque no exista una garantía personal (del patrimonio del receptor de los recursos), sí que existe lo que podríamos llamar una garantía moral del prestatario, que se compromete a su devolución.

- Todo lo anterior no invalida la aplicación de técnicas que, si bien no reciben la denominación de garantías, sí que motivan la devolución de los fondos. Entre otras pueden destacarse:

- La existencia de grupos solidarios. Como en el Grameen Bank, los préstamos se realizan a grupos: sólo uno de los componentes lo recibe inicialmente y, cuando lo ha devuelto, lo van recibiendo los restantes miembros del grupo. En consecuencia los componentes del mismo "presionan" su devolución; al mismo tiempo, los mismos prestatarios se organizan en grupos en los que tienen cierta certeza de devolución.

- Los préstamos progresivos: inicialmente, las cantidades prestadas son muy reducidas con la promesa de que si se reembolsan las cantidades en tiempo y forma se irán percibiendo cantidades superiores en el futuro.

- En otras ocasiones se obliga a un cierto nivel de ahorro que actúa como garantía de devolución. 
Las experiencias sobre la cuestión de las garantías en el ámbito de los microcréditos son muy variadas, ya que, en definitiva, en cada caso se ha buscado lograr la supervivencia de la entidad que presta los recursos. En última instancia, cabría hablar de que los microcréditos están basados en lo podríamos llamar el crédito "relacional", el cual está basado en la confianza mutua entre las dos partes de la operación y que implica, como ya se ha visto, la necesidad de cercanía entre los agentes, pero que también tiene consecuencias tanto desde el punto de vista de los costes en los que se incurre (lo que a su vez tiene efectos sobre los beneficios y sobre la viabilidad de la entidad microfinanciera), como desde una perspectiva financiera, debido a una posible concentración de riesgos en determinadas actividades o zonas geográficas.

El "problema" puede encontrarse en la ausencia, en determinados casos, de unas normas de regulación y supervisión que incidan en este aspecto (salvo que las entidades que conceden los microcréditos sean entidades de crédito, en muchos casos no están sometidas a una regulación específica de su actividad). ¿̇Hasta qué punto sería necesaria una regulación de estas entidades que viniera a cubrir esta circunstancia? Aunque parece que, según los informes sobre el sector, las tasas de morosidad son reducidas, ¿̇serían necesarias medidas como la dotación de provisiones para la cobertura de morosos o posibles fallidos?

Otro peligro que puede aparecer en algún caso (como en los mercados más competitivos de Hispanoamérica -Perú y Bolivia-) es el sobreendeudamiento de los prestatarios, que pueden acudir a varias entidades en un corto periodo de tiempo, las cuales le conceden la financiación en su afán por competir. En este sentido, podría ser interesante el empleo de instrumentos como las centrales de información de riesgos o similares.

\subsection{La rotación de los créditos}

Otro aspecto importante que conviene tener en cuenta es la rotación de los fondos, la cual viene determinada por dos circunstancias: por una parte, los importes concedidos en las operaciones de microcrédito, como ya se ha indicado, son reducidos; por otro lado, el plazo de devolución también es corto y hay una periodicidad elevada en la forma de reembolso de los fondos (semanal, quincenal en muchos casos). Esto da lugar a que el índice de rotación de la cartera sea elevado, lo que trae consigo varios efectos:

- En relación con los costes, la gestión de la cartera se hace más compleja al constar de un elevado número de operaciones, lo que eleva los costes operativos y de administración. Para solventar este problema es necesario actuar buscando sistemas de información que permitan reducir estos gastos.

- Esta presión sobre los costes trae, a su vez, efectos sobre los tipos de interés de las operaciones, elevándolos, ya que, en cualquier caso, la entidad debe buscar su autosuficiencia operativa, esto es, la cobertura de los costes de funcionamiento.

- Por último, también deben destacarse las consecuencias sobre la estructura de los recursos con los que financiar la concesión de microcréditos: en algunos casos se ligan éstos a la realización de depósitos que no pueden retirarse hasta la finalización de la operación. En 
otros casos, la estructura de los recursos puede condicionar la posibilidad de la concesión de préstamos; en todo caso, es necesario contar con una base de recursos (propios, ajenos remunerados o ajenos procedentes de donaciones y subvenciones) estable, puesto que en caso contrario, los problemas de liquidez o de falta de recursos podrían limitar la supervivencia de la entidad.

\subsection{La procedencia de los recursos: los prestamistas}

Ya se ha indicado que en una entidad bancaria tradicional, los recursos para financiar las inversiones tienen dos orígenes: los recursos propios (básicamente, capital o aportaciones de los fundadores y reservas) y los recursos ajenos (fundamentalmente, en forma de depósitos de distintas modalidades y emisión de valores). Los primeros se destinan sobre todo al inmovilizado, al efectivo y a las inversiones en valores, mientras que los segundos corresponderían más bien a la financiación de inversiones y consumo de los clientes a través de los créditos. De esta forma se realiza la labor de intermediación financiera.

En el caso de las entidades que conceden microcréditos, esta distinción no es tan sencilla, ya que las instituciones son de distinto tipo y, en cada una de ellas, los recursos proceden de fuentes diferentes. Distinguimos entre tres casos: organizaciones no gubernamentales (ONG), instituciones financieras especializadas y entidades de crédito.

\subsection{Las organizaciones no gubernamentales}

En el caso de las ONG, se trata de entidades sin ánimo de lucro, en las que lo que predomina es su finalidad de promoción social y económica. Para ellas los microcréditos son un instrumento que contribuye al logro de sus fines y no su operación habitual, lo que lleva aparejado consecuencias de diversa índole.

Desde el punto de vista de la financiación, los recursos de las ONG proceden fundamentalmente de donaciones; por lo tanto no son fondos reembolsables, lo que en principio, puede facilitar la realización de operaciones. Sin embargo, existe una limitación al volumen de microcréditos que se pueden conceder, ya que las ONG no cuentan con la posibilidad de captar recursos ajenos. Además, el hecho de que los fondos procedan de donaciones también puede suponer un límite a la hora de captar más recursos si éstos fueran necesarios; por otro lado, esta circunstancia no debe diluir la responsabilidad de la entidad frente a sus donantes, que en todo momento deben conocer el destino de los fondos aportados y el "buen uso" de los mismos.

Las ONG pueden considerarse como pioneras en la concesión de microcréditos; debido a esta circunstancia, cuentan como ventajas su cercanía a los prestatarios y su mayor flexibilidad, así como una mayor especialización en estas operaciones, todo esto a su vez se ve favorecido por el hecho de que no están sometidas a la autoridad financiera ni a las normas que regulan la actividad de instituciones de crédito. No obstante, si no buscan la autosuficiencia financiera, pueden prestar los fondos por debajo del tipo de interés de mercado, lo que puede traer consigo problemas de estabilidad a largo plazo. 


\subsubsection{Las instituciones financieras especializadas}

Normalmente, las instituciones financieras especializadas en microcréditos surgen de la transformación de las ONG en entidades de microfinanzas, como una vía para conseguir un mayor alcance en su actividad, esto es, llegar a un número más amplio de beneficiarios. Por lo tanto, tienen mayor tamaño y, consecuentemente, más posibilidades de actuación pues generalmente pueden acceder a los mercados financieros para captar los recursos que necesitan para el desarrollo de su actividad.

En estos casos, los fondos de los que se nutren los microcréditos proceden en parte de donaciones, como en el caso anterior, pero otra parte tiene su origen en recursos ajenos reembolsables. Éstos, a su vez, pueden proceder de préstamos blandos o de operaciones de depósito (en muchas ocasiones vinculados a los mismos microcréditos) lo que implica que existe ya una labor de intermediación financiera más próxima a lo que sería el esquema bancario tradicional.

En consecuencia, estas entidades deben tener unos criterios de funcionamiento más cercanos a los de las entidades de crédito tradicionales; en concreto, están sometidas a la supervisión de la autoridad correspondiente, generalmente deben cumplir todos los requisitos establecidos por la regulación (esto es especialmente importante si, además están autorizadas a captar depósitos) y, en definitiva, su actuación no sólo estará guiada por su finalidad social, sino que deberán buscar la autosuficiencia que les permita sobrevivir a largo plazo.

\subsubsection{Entidades de crédito}

En este caso nos encontramos ante entidades de crédito que realizan operaciones de microcréditos. En consecuencia, estas instituciones son las mismas que realizan las operaciones más conocidas habitualmente (descritas en lo que sería el esquema bancario tradicional) y que, aunque realicen una actividad (los microcréditos) que en parte es diferente a la habitual, no ven modificadas ni su regulación (cumplimiento de coeficientes, solvencia, etc.) ni el régimen de supervisión al que están sometidas. Por otro lado, al estar orientadas hacia la supervivencia, están "obligadas" a obtener unos beneficios que la garanticen.

Las formas en las que las entidades de crédito conceden operaciones de microcrédito son variadas, pero pueden resumirse básicamente en tres modelos ${ }^{6}$ :

1. Los microcréditos se garantizan con los recursos propios de la entidad financiera y se cubre el coeficiente de solvencia al igual que en cualquier otro préstamo. Normalmente, no existen avales y la única garantía existente es de tipo moral y procede de la entidad de apoyo que presenta el proyecto (modelo de La Caixa).

2. Los microcréditos se incluyen dentro de la actividad crediticia habitual (por lo tanto, se reflejan dentro del balance de la entidad financiera) y se cubren con recursos propios al igual que los restantes, con la salvedad de que existe, además, un aval por alguna de las fundaciones

\footnotetext{
${ }^{6}$ Nos fijamos en este caso en las operaciones realizadas por entidades de crédito en España, cuyas principales características se resumen a continuación en el punto 3 .
} 
que ha sido creada con tal fin con cargo a los presupuestos de la Obra Social. En este caso, por lo tanto, es la Fundación la que avala los proyectos y suele tener, a su vez, un convenio de colaboración con alguna entidad de apoyo (modelo de la BBK).

3. Los recursos para la concesión de microcréditos proceden de un fondo social que a su vez se encuentra en una fundación de la entidad financiera dotado por la Obra Social. En consecuencia, los microcréditos están separados de lo que sería la actividad financiera habitual de la entidad, por lo que no es necesario que se garanticen con los recursos propios de la entidad (modelo de Caja Granada).

Una primera cuestión que cabría hacerse en este caso es por qué se observa una participación creciente de la banca tradicional en este tipo de operaciones. Una primera explicación puede encontrarse en que los agentes hasta ahora "excluidos" constituyen un nicho de mercado al que atender, que no presenta unos niveles de riesgo tan elevados como en un principio se les achacaba, según la información que se deriva de la experiencia acumulada. En segundo término cabe aducir que las entidades de crédito "tradicionales" pueden contar con ventajas competitivas para penetrar en este segmento con éxito, al menos en un país como España: amplias redes de sucursales, recursos suficientes, sistemas de información y tecnología avanzada, etc. Finalmente, la creciente competencia en el negocio tradicional ha provocado un estrechamiento de los márgenes que ha presionado hacia la búsqueda de nuevos mercados.

Cuando las entidades de crédito se plantean participar en estas operaciones deben tener presentes ciertas cuestiones que condicionarán su éxito en el mismo. Así, las características de los demandantes son distintas a las habituales, y a ello deben adaptarse: aumentar el conocimiento de los clientes (actividad, voluntad de pago, etc.), para lo que debe aumentar su cercanía al mismo; diseñar herramientas que incentiven la devolución de los fondos; simplificar los mecanismos de prestación del servicio, para lograr la reducción de costes; descentralizar la toma de decisiones; especializar al personal; adecuar las cantidades, periodicidad de las cuotas, etc. a las personas de bajos ingresos.

Esta adaptación no siempre resulta fácil ni se lleva a cabo totalmente por parte de las entidades, de ahí que surjan, por ejemplo en España, vías de colaboración con otros agentes especializados en microfinanzas (como ONG), de forma que ambas partes salen beneficiadas. De esta forma, la distribución de los microcréditos se articula, por lo general, contando con entidades de apoyo, que pueden ser instituciones sin ánimo de lucro de carácter público, sindicatos, asociaciones u ONG de carácter privado, con experiencia en inserción social y laboral. Las instituciones que forman estas redes de apoyo han sido calificadas de diversas formas, como por ejemplo, instituciones de asistencia social, "partners" sociales o centros colaboradores.

\section{Los microcréditos en España}

Es evidente que la situación de pobreza y exclusión en los países desarrollados como España es distinta de la existente en los países del tercer mundo o en vías de desarrollo. Por esta razón, una cuestión previa es distinguir las operaciones de microcrédito realizadas en España de las 
realizadas por entidades españolas en otros países, como los que están en vías de desarrollo o del tercer mundo. Centrándonos en las primeras, los microcréditos, como instrumento que ayuda a paliar estas situaciones de pobreza, presentan algunas particularidades que les hacen en parte diferentes a los descritos en el apartado 2 (que corresponderían esencialmente a los microcréditos realizados en las otras naciones citadas). De esta forma, las principales características de los microcréditos realizados en España son las siguientes:

- Por lo general, se trata de préstamos individuales para poner en marcha microempresas que generen autoempleo y empleo.

- Los beneficiarios suelen pertenecer a ciertos grupos sociales. Así, los principales requisitos del público al que se destinan los recursos son: a) formar parte de colectivos sociales desfavorecidos y con especiales dificultades de inserción laboral (mujeres, inmigrantes, parados de larga duración, mayores de 45 años, hogares monoparentales, discapacitados, minorías étnicas, y otras personas en situación de pobreza y marginación social); b) no tener acceso al sistema financiero formal por falta de avales o garantías; $y$ c) tener espíritu emprendedor y disponer de una iniciativa empresarial viable.

- Los importes concedidos son reducidos, pero claramente mayores que los de países poco desarrollados. Así, los créditos oscilan entre los 8.000 y los 25.000 euros.

- El plazo de la operación también es reducido, si bien puede llegar a varios años, y en ocasiones con periodos de carencia, lo cual es lógico debido a que los trámites necesarios para la puesta en marcha de las empresas son más largos que en otros países (como los que están en vías de desarrollo). Entre las entidades españolas, el plazo máximo de reembolso varía de 3 a 5 años y los períodos de carencia pueden llegar a los 6 meses.

- Los tipos de interés son similares a los de mercado o algo inferiores (en los últimos años se situaban entre el 4 y el $6 \%$ ). Además, generalmente no se aplican comisiones de ningún tipo 0 , si existen, son subvencionadas.

En los últimos años, se ha constatado en España un crecimiento de las operaciones de microcréditos, realizadas en su mayor parte por cajas de ahorros, aunque también los bancos los han concedido, sobre todo canalizando los recursos de la línea de microcréditos del Instituto de Crédito Oficial (ICO). No obstante, puede afirmarse que son las cajas las principales impulsoras de estas operaciones en nuestro país, lo cual es una consecuencia lógica de su carácter social 7 . Por otra parte, las entidades de crédito españolas han abierto también vías de colaboración con otros agentes especializados en microfinanzas (como las $\mathrm{ONG}$ ) de forma que ambas partes salen beneficiadas.

\footnotetext{
7 Las fuentes de financiación de los programas de microcréditos son, en la mayoría de los casos, los fondos procedentes de la Obra Social de las cajas. Por tanto, son recursos que, dentro de su función social, se destinan a evitar la exclusión financiera, y fomentar el desarrollo económico y el progreso social y no forman parte de la actividad financiera habitual de las cajas de ahorro. En otras ocasiones, los fondos provienen de convocatorias de proyectos sociales de organismos públicos (es el caso de Caja Granada que financia en parte su programa de microcréditos a través del programa Equal de la Unión Europea).
} 
Las cajas de ahorro distribuyen los microcréditos, por lo general, a través de redes de apoyo formadas por instituciones sin ánimo de lucro, bien de carácter público ${ }^{8}$, como los organismos dependientes de Comunidades Autónomas, Diputaciones o Ayuntamientos (consejerías de empleo, agencias de desarrollo local o similares), o bien con sindicatos, asociaciones u ONG de carácter privado, con experiencia en inserción social y laboral.

Estas instituciones de apoyo sirven de enlace entre los beneficiarios finales y las instituciones financieras, al tiempo que actúan ofreciendo una especie de aval a los proyectos financiables, no tanto en el sentido jurídico del término, sino en cuanto que realizan labores tales como: recibir a los potenciales beneficiarios y recabar información sobre los mismos y sobre la idea de negocio, con el fin de determinar su idoneidad; prestar asesoramiento y asistencia técnica al beneficiario en la definición y elaboración de un plan de negocio viable; estudiar y validar la viabilidad económica del plan de negocio presentado ante las entidades de crédito para su financiación; y una vez concedido el microcrédito, realizar el seguimiento y la asesoría técnica de las iniciativas financiadas durante el período de vida del mismo.

Evidentemente, todas estas tareas requieren, a su vez, del apoyo técnico y financiero por parte de las entidades de crédito a las propias instituciones de apoyo para que puedan ofrecer un buen servicio a los beneficiarios y ayuden a una favorable ejecución de los proyectos financiados, lo que puede contribuir a reducir los riesgos de las operaciones y minimizar el número de fallidos.

Además de lo expuesto, también los microcréditos han sido empleados en España por parte de la administración pública como un instrumento de ayuda a las iniciativas empresariales de ciertos colectivos. En este sentido se han realizado dos iniciativas: la Línea de Microcréditos del ICO y el Programa de Microcréditos para Mujeres Emprendedoras y Empresarias, promovido por el Instituto de la Mujer en colaboración con la Dirección General de la Pequeña y Mediana Empresa (DGPYME) del Ministerio de Economía; ambas pueden ser consideradas como herramientas de política económica para luchar contra el desempleo, a través del autoempleo, y para mejorar las condiciones de vida de algunos grupos sociales.

\section{Conclusiones}

Si bien existen algunas voces que realizan una fuerte crítica a los microcréditos, en especial en los países menos desarrollados, por considerar que no cumplen las ventajas que se les suelen atribuir, parece generalmente aceptado que, utilizados adecuadamente y a pesar de ciertos inconvenientes, pueden considerarse como una herramienta adecuada para contribuir a reducir los niveles de pobreza. De todas formas, éste es un tema controvertido; las operaciones de microfinanzas, que no siempre coinciden con los microcréditos, parece que no han contribuido demasiado a la reducción de la pobreza. Sin embargo, en la actuación del Grameen Bank y algunas otras entidades sí se han observado resultados importantes en cuanto a dicho proceso de reducción de la pobreza.

${ }^{8}$ A modo de ejemplo, la red de apoyo de la Fundación Un Sol Món está formada por un total de 50 entidades de apoyo configurada en su mayoría por ayuntamientos de Cataluña. 
No obstante, lo que sí es claro es que, para que puedan tener éxito en su propósito, los programas de microcréditos deben diseñarse ajustándose a las características sociales, culturales y económicas del lugar en el que vayan a aplicarse, ya que la generalización de sus condiciones puede llevar a un fracaso. Por este motivo, por ejemplo, es razonable contemplar que exista, como se hace en algunos casos en España, un periodo de carencia, debido a la duración de los trámites de constitución de las empresas y a que siempre transcurre un cierto tiempo hasta que empiezan a generarse beneficios. Si no se hiciera así, podría suceder que los créditos resultasen fallidos o que los recursos se destinasen a agentes que no cumplen requisitos como los comentados antes, ya que lo que primaría sería intentar asegurar el cumplimiento de la devolución de los fondos. Efectivamente, a veces surgen problemas en cuanto al destino final de los fondos aportados, sobre todo si se trata de financiar un proyecto ejecutado durante un tiempo determinado y en el que la devolución del crédito se realiza a la finalización de dicho proyecto.

También parece razonable que la concesión de los microcréditos vaya acompañada de un programa de asistencia o formación en la gestión empresarial y de apoyo técnico a los beneficiarios. Esta tarea, que ya se viene realizando en algunos casos por las denominadas redes de apoyo, debe estar bien dotada en cuanto a capacidades técnicas, recursos materiales y apoyo económico por parte de las entidades financieras.

Otra cuestión importante es el compromiso adoptado por las entidades financieras en su apuesta por este instrumento. Puesto que muchas instituciones financieras canalizan el microcrédito a través de la obra social, ciertas fundaciones o los departamentos de responsabilidad social corporativa, podría pensarse que se trata de operaciones que contribuyen a mejorar su "imagen" o su reputación, en lugar de considerarlos como un producto más dentro de sus operaciones habituales. Para evitar esto, debería buscarse que los microcréditos fuesen el fruto de un compromiso frente a la sociedad y una profesionalización (por ejemplo, realizando una selección eficiente de los clientes, mejorando la eficiencia administrativa y las herramientas de gestión, adaptando los productos a las necesidades de los beneficiarios, combinando los microcréditos con otros servicios financieros, etc.), de forma que se apoyen iniciativas viables, capaces de generar rentabilidad tanto para las entidades que otorgan el crédito como para los propios beneficiarios.

Por otra parte, teniendo en cuenta cómo se suelen plantear actualmente los microcréditos por parte de las entidades de crédito "tradicionales", se pueden citar algunos problemas de estas operaciones tanto desde el punto de vista de los recursos, como desde el de la solvencia.

Desde la primera perspectiva, las vías de financiación con las que cuentan estas operaciones son limitadas, ya que normalmente no se nutren de los recursos ajenos. Por ejemplo, si nos fijamos en la reciente creación de una fundación por parte del BBVA que se va a especializar en operaciones de microcréditos en Latinoamérica a través de participaciones, generalmente mayoritarias, en entidades que trabajan en microfinanzas, el importe que se va a destinar a este fin es inicialmente 200 millones de euros, lo cual ha sido calificado de una "gran aportación"; sin embargo, esta cantidad resulta muy reducida si se compara con los 1.045 .000 millones de euros a los que ascendían los recursos ajenos de los bancos españoles a 31-8-2006. 
Desde el punto de vista de la solvencia, si los microcréditos se incluyesen en el balance, en otra palabras, si se realizasen como el resto de las operaciones "tradicionales", se plantearían también problemas pues, a pesar de que en ellos las tasas de morosidad no sean muy elevadas, sí que es cierto que las garantías son menores que en otras operaciones y el grado de solvencia de las entidades se resentiría. En otras palabras, un crecimiento de los microcréditos como operaciones dentro del balance, haría que el sistema financiero fuese más vulnerable, corriendo el riesgo de una crisis sistémica. Ante esto, cabría plantearse si sería adecuado una modificación de las actuales normas a las que antes se ha aludido, pero, como también se ha comentado, las recientes regulaciones (Basilea II) no parecen ir por esa vía de disminución de las exigencias.

En resumen, las dificultades de incorporar las operaciones de microcrédito al sistema tradicional quedan claras en el siguiente ejemplo: la expansión de créditos en zonas rurales de la India a través de la banca nacionalizada comprometió los resultados de esta banca, lo que obligó a su privatización. Es evidente que, como hemos indicado, las operaciones de microcréditos precisan entidades especializadas o su inclusión en operaciones fuera de balance de las citadas instituciones del sistema tradicional.

Finalmente, como se indica en algunos foros, los microcréditos deben convertirse en una herramienta eficaz de sensibilización sobre un ahorro más ético y responsable por parte de la sociedad, pues parece mucho más efectivo, en la lucha contra las causas de la exclusión y el empobrecimiento, el plantearse un ahorro ético y responsable, en el que los préstamos promuevan ciertos valores éticos o culturales, promuevan la creación de empleo estable, la generación de ingresos en los pobres, el cuidado del medioambiente y el fomento del asociacionismo, el cooperativismo y la solidaridad en general. Actualmente una parte importante de los recursos que se asocian a una finalidad de carácter social se dirigen hacia los fondos de inversión de carácter ético o solidario, pero sería de gran interés dirigirlos hacia otras experiencias más relacionadas con lo que se conoce como banca ética, en la que las operaciones están ligadas a finalidades como las mencionadas más arriba.

\section{Bibliografía}

Confederación Española de las Cajas de Ahorros (2003), Memoria de la Obra Social de las Cajas de Ahorro.

DelFiner, M., PAILHÉ, C. Y Perón, S. (2006), "Microfinanzas: un análisis de experiencias y alternativas de regulación", XXI Jornadas Anuales de Economía del Banco Central de Paraguay, mimeo.

Fernández Olt, B. (2006), "Microfinanzas: diferencias Norte-Sur", I Seminario sobre Microcréditos organizado por ASOLCOR, Córdoba, mimeo.

Foro NANTIK LUM DE MICROFINANZAS (2004), Los Microcréditos: alternativa financiera para combatir la exclusión social y financiera en España. Descripción de las principales iniciativas, Cuadernos Monográficos n. ${ }^{\circ}$, Madrid, edit. Foro Nantik Lum de Microfinanzas. 
Foro NantiK Lum de Microfinanzas (2005a), Los microcréditos en España, Principales Magnitudes 2004, Barcelona, edit. Obra Social "la Caixa".

Foro Nantik LUm de Microfinanzas (2005b), Glosario básico sobre microfinanzas, Cuadernos Monográficos n. ${ }^{\circ}$ 5, Madrid, edit. Foro Nantik Lum de MicroFinanzas.

García García, A.C. y García Gómez, A. (edits) (2006), Las cajas de ahorros españolas y las microfinanzas, Granada, edit. Caja Granada.

GómEz GIL, C. (2005), Los microcréditos en la cooperación para el desarrollo, Córdoba, edit. Ayuntamiento de Córdoba

GutiérRez, B. (2001), Instrumentos financieros alternativos, [en línea] 5campus.org, Finanzas <http://www.5campus.org/leccion/nolucra4> [consulta en enero 2007].

lacalle CalDerón, M.C. (2002), Microcréditos. De pobres a microempresarios, Barcelona, edit. Ariel.

LaCalle CALDeRón, M.C. (2002), "Los microcréditos: una posibilidad de trabajo y mejora económica para la familia", Revista de Fomento Social, n 57, pp. 65-84.

LATIFEE, H.I. (2006), The Future of Microfinance: Visioning the Who, What, When, Where, Why, and How of Microfinance Expansión Over the Next 10 Years, ponencia en la Cumbre Global del Microcrédito 2006.

Yunus, Muhammad (1999), Hacia un mundo sin pobreza, Barcelona, edit. Andrés Bello. 